\title{
REVIEW I The History of Live Music in Britain Volume II, 1968-1984: from Hyde Park to the Hacienda
}

\author{
Simon Frith, Matt Brennan, Martin Cloonan and Emma Webster
}

Abingdon: Routledge, 2019

ISBN: $9781409425892(\mathrm{HB})$

\author{
Alison C. Eales \\ alison.eales@gmail.com
}

This book is the second in a three-volume series that aims to address a gap identified in the literature. While the title gives some indication of that gap - the history of live music in Britain - it does not quite capture the multiple focuses that are richly interwoven throughout this text. Drawing on a range of disciplinary and professional backgrounds that include history, sociology, journalism, performance, music promotion and band management, the authors have focused on the social and cultural role of music in Britain. This is arguably a more important point of focus than the 'liveness' of the music discussed, particularly given the various influences of recording, broadcast and music videos on the live sector, all of which are given careful consideration here. The book is also characterised by a focus on the production, rather than the consumption, of live music, though there is sufficient content about audiences and reception to avoid a sense of imbalance.

A further focus (perhaps an unsurprising one, given that all the authors work extensively in popular music studies) is popular music, though this is certainly not to the exclusion of other musical forms. The authors make a compelling argument for placing the emphasis on rock music in particular. 1968-1984, they suggest, was the age of rock, ushering in new artistic conventions, audience expectations, economic implications and industry apparatuses that had implications for the production of many other forms of music. This case is made in the first chapter, and evidence of the impact of rock is embedded throughout the rest of the book. Pop music continued to flourish during this period, and it is arguable that had the book's emphasis been on consumption rather than production, the focus on rock might have been less convincing. 
Like the first volume in this series (Frith et al. 2013), published in 2013 and covering the period 1950 to 1967, the book is structured thematically rather than chronologically. Inevitably there is some overlap between chapters, but this contributes to a sense of coherence rather than repetitiveness and serves to strengthen the book's central arguments. Its ten core chapters revisit some of the topics covered in Volume 1, including the relationship between live music and the state, the role of do-it-yourself music-making in the live sector and, of course, venues. As with Volume 1, these core chapters are interspersed with short 'snapshots' of three UK cities (Bristol, Glasgow and Sheffield) and an account of a Rolling Stones concert. In Volume 1, the city snapshots reflected the musical life of the cities during November 1962, and the Stones concert was their 1963 residency in Richmond. Here, the city snapshots relate to November 1976, and the Stones concert is their run of shows at Earls Court in May 1976. These break up the body of the text and provide additional local colour and detail, though there is plenty of this throughout.

The book draws upon a thorough and varied body of research, with a good balance of contemporary and retrospective sources, including a series of original and illuminating research interviews. It is written in clear, accessible language, and includes material (particularly from the research interviews) that captures just how lively the world of live music can be. It would, perhaps, have benefited from the inclusion of a clear opening statement of its aims, scope and key definitions (as appeared in the Preface to Volume 1); while part of a series, it also functions as a standalone volume, with its central themes and arguments, and some readers will approach it as such. The argument for the inclusion of discos under the umbrella of 'live music', for example, is not stated in the book beyond a reference to Volume 1 (pp. 142-3).

The rationale for choosing Bristol, Glasgow, and Sheffield for the snapshots is also not made clear but offers the impression that this volume is concerned primarily with live music in urban settings. This is generally true (and perhaps understandable) and could have been stated explicitly. Conversely, given the book's general focus on cities, it might have been more interesting to choose some contrasting places for these local case studies, illustrating what forms of live music might have typically been available to audiences in rural or coastal areas as well as cities.

A reference to Chris Steele-Perkins' 'classic photograph' of the 1974 Brixton Reggae Festival (p. 99) does rather make the reader question why the photograph itself has not been included in the book (other than as a web address) and illustrates something of a drawback for this volume. Live music is of course a multi-sensory experience, and while not all aspects of this experience can be reproduced in print, to fail to include any visual content at all seems a missed opportunity. Inevitably, the importance of venues is a key theme in the book, and photographs and floor plans illustrating the different kinds of spaces being discussed would have greatly enriched the text. This would have been particularly valuable in the chapter concerning clubs: variety clubs, for example, represent a peculiarly British (and obsolete) type of venue, for which not all readers will have a visual frame of reference. Maps showing the locations of the venues under discussion would also have given the city snapshots more substance.

A final criticism is that the book would have benefited from closer editing and proofreading: sentences are occasionally ambiguous, and some passages tend towards descriptive lists of examples. This is nevertheless a minor distraction in 
what will likely prove to be a landmark text for scholars of live music as well as for social historians.

\section{References}

Frith, S. et al. 2013. The History of Live Music in Britain, Volume I: 1950-1967: From Dance Hall to the 100 Club. Abingdon: Routledge. 